\title{
UMA EXPERIÊNCIA NA AULA DE PLE: A SENSIBILIDADE E A EMOTIVIDADE NAS AULAS DE LEITURA E ENSINO DOS VERBOS NOS PRETÉRITOS PERFEITO E IMPERFEITO
}

\section{Sueli FIRMINO*}

- RESUMO: Neste artigo, trato de mostrar a minha experiência com uma atividade de sensibilização em uma aula de leitura de um curso de PLE (Português como Língua Estrangeira) para alunos de origem hispânica, desde o planejamento até o momento da avaliação, orientando as atividades ao longo do processo. Separei as etapas desse processo desde o reconhecimento do perfil dos alunos (trabalhamos com dois grupos específicos de nível intermediário), a escolha do material a ser trabalhado, as estratégias usadas, a dinâmica aplicada e a avaliação feita oralmente onde, para minha surpresa, a sensibilidade dos alunos naquele momento gerou um clima de emotividade muito importante, resultando num ambiente de confiança e cumplicidade. Muitas vezes esses sentimentos estáo afastados de uma sala de aula, deixando que a distância da relação professor-aluno-colega seja um fator de inibição na hora da prática oral do idioma que está aprendendo. A proximidade entre as pessoas propicia um ambiente acolhedor, agradável e o clima mais propício para que haja mais interação e, consequentemente mais emotividade.

- PALAVRAS-CHAVE: Leitura. Emotividade. Sensibilidade. Competência oral.

\section{Introdução}

Não sei se a vida é curta ou longa demais para nós, mas sei que nada do que vivemos tem sentido, se não tocarmos o coração das pessoas.

Cora Coralina (2011, p.243).

Não é tarefa simples, nem cabe em poucas linhas, contar as experiências dessa profissão tão desafiante que é ser professor (a) de língua portuguesa para estrangeiros, sobretudo estando imerso na cultura dos estudantes.

Como experiência, tenho que admitir, e faço questão de ressaltar sempre isso, que durante esses 30 anos de magistério, dos quais 16 deles como professora de PLE

* US - Universidad de Sevilla. Sevilha - Espanha. 41004 - sueliayalas@gmail.com 
português como língua estrangeira, fui aprendendo com meus colegas e, principalmente, com meus alunos a levar em consideração o sentimento e o lado lúdico das pessoas que se propóem a aprender um idioma estrangeiro.

Com o tempo fui trabalhando esse aspecto com mais emotividade, com mais criatividade e observei que os resultados eram sempre positivos e o feedback era imediato. Quando tinha a aula preparada, só precisava chegar o momento de executála, tudo estritamente muito bem pensado e planejado.

Ora, quem é professor sabe muito bem que entre a aula preparada e a aula no seu momento em si, existe um abismo extremamente indecifrável... A gente nunca sabe se a aula vai ser perfeita como gostaríamos e, em geral, nunca é.

Se o professor tiver sua sensibilidade bem aguçada, ele vai perceber o que o aluno necessita no momento da sua aula: se uma leitura sobre um determinado assunto, se uma explicação gramatical sobre o assunto que viu na aula passada, se o aluno náo assimilou o conteúdo trabalhado, se está cansado e precisa de um jogo relacionado a seu programa para descontrair e estar atento à sua aula, se é necessário o trabalho com uma música, porque hoje o dia foi tenso, se um vídeo, etc.

O professor que percebe esse momento de início de aula vai perceber imediatamente se sua aula preparada vai acontecer ou não. E se ele for daquele tipo que, com muito jogo de cintura vai tirar das mangas uma aula improvisada, pode ter certeza que vai sair orgulhoso da sua aula nesse dia e o aluno vai agradecer essa sua sensibilidade, além de perceber que existem diversas formas de aprendizado de um idioma e que, nem sempre, todos os dias têm que ser iguais.

Não se trata de nenhuma novidade, nem do descobrimento do maior tesouro no mundo do ensino de PLE. Há muita gente nesse campo que já trabalha dessa maneira.

Por tudo isso, a proposta deste trabalho é relatar uma experiência pessoal, de uma aula dada há pouco tempo a dois grupos de alunos de origem hispânica e não, exatamente, de apresentar teorias novas sobre o ensino de PLE.

\section{O aluno (ou o grupo de alunos)}

Existem várias formas de planejamento de uma aula de PLE, quando um dos objetivos a ser trabalhado é a competência oral, ou seja, fazer o aluno falar na língua que está aprendendo.

Em minha opinião, o professor deve, antes de tudo, conhecer seus alunos para poder fazer um bom planejamento da sua aula e, desse modo, conseguir alcançar a meta desejada. Sabemos, obviamente, que cada pessoa (no caso de um grupo) vai ter uma reação distinta diante dos desafios propostos, vai falar ou não sobre assuntos mais pessoais, etc. O importante é que o professor crie e propicie um clima favorável, sem expor o aluno a situaçóes constrangedoras ou comprometedoras.

De certa forma, os alunos de PLE, que estáo no nível intermediário, que são os que começam a pensar em português, não têm problemas em contar alguma coisa 
relacionada à sua vida profissional e, muitas vezes, à sua vida privada. Aliás, muitos dizem que preferem contar algo que tenha lhes acontecido, para não ter que inventar, pois, nesse caso, teriam dois trabalhos: inventar e depois ter que passar para o português.

No caso de um aluno particular, o professor precisa deixá-lo à vontade, criando um clima ameno e procurar que o assunto não seja muito cansativo, pois o aluno pode desanimar e a aula não será nada produtiva. É muito importante o tempo estimado para esse tipo de atividade, pois para um aluno individual, o tempo geralmente é menor que para um grupo.

Uma vez que o professor já conhece seu aluno (ou seu grupo), poderá traçar seus objetivos e separar as atividades convenientes para o assunto escolhido.

A emotividade começa a partir desse momento: a escolha adequada de materiais relacionados ao assunto a ser estudado na sua aula. Provocar no aluno euforia ou excitação por falar e praticar o idioma vai fazê-lo se sentir mais seguro, mais confiante e vai liberar a ansiedade contida quando aprendemos um novo idioma e percebemos que pouco a pouco somos capazes de nos comunicar e fazer-nos entender.

A excitação nos leva a um sentimento de força, aumentando dessa forma o nível de atividade e - acrescento por experiência - o nível de criatividade também: é o que nos diz Vigotsky:

[...] es muy importante tener en cuenta que en un periodo de gran excitación se suele sentir una fuerza colosal. Ese sentimiento aparece de repente y lleva al individuo al más alto nivel de actividad. En el momento en que aparecen emociones muy fuertes, la excitación y el sentimiento de fuerza se fusionan liberando la energía almacenada [...] (VIGOSTSKY, 2004, p.12).

\section{Planejando e preparando a aula}

Para ilustrar este artigo com um exemplo prático, selecionei o assunto: leitura de textos curtos e revisáo dos tempos verbais estudados, com ênfase nos verbos nos tempos do pretérito perfeito, imperfeito e no presente do indicativo e no modo imperativo.

Utilizei um texto, uma letra de música e a dinâmica que detalho no decorrer deste trabalho.

\section{Perfil dos alunos}

A aula foi preparada para dois grupos de alunos (espanhóis e sul-americanos) de nível intermediário, em um curso de PLE que ministro na cidade de Madri (Espanha).

O primeiro grupo é formado por seis alunos (três espanhóis, dois venezuelanos e uma peruana) que trabalham em uma multinacional brasileira com escritório em 
Madri. É um grupo dinâmico e que costuma dar bons retornos às atividades que lhes são apresentadas nas aulas. Eles têm três horas de PLE por semana e são muito participativos. Trabalham em setores diferentes e entre eles há sempre uma boa relação.

O outro grupo é formado por um só aluno, presidente executivo de uma consultoria espanhola que tem escritório no Brasil. O aluno tem três horas de PLE por semana e é muito aplicado. No começo, era muito tímido e dizia que falar um idioma estrangeiro era um drama, mas esperava que com o português fosse diferente.

\section{A escolha dos textos}

Essa escolha do texto a ser utilizado é fundamental para que a aula faça ou náo o sucesso que o professor espera. Tudo é válido: textos literários clássicos ou contemporâneos, jornalísticos, poemas, letras de música. Como já é sabido, quanto mais variamos os gêneros textuais e quanto mais atuais e significativos sejam estes, melhor.

O primeiro texto escolhido desta vez foi tirado de um site na Internet:

\section{UMA LIÇÃO DE VIDA}

Uma senhora idosa, elegante, bem vestida e penteada, estava de mudança para uma casa de repouso, pois o marido com quem vivera 70 anos havia morrido e ela ficara só

Depois de esperar pacientemente por duas horas na sala de visitas, ela ainda deu um lindo sorriso quando uma atendente veio dizer que seu quarto estava pronto. A caminho de sua nova morada, a atendente ia descrevendo o minúsculo quartinho, inclusive as cortinas de chintz florido que enfeitavam a janela.

- Ah, eu adoro essas cortinas - disse ela com o entusiasmo de uma garotinha que acabou de ganhar um filhote de cachorrinho.

- Mas a senhora ainda nem viu seu quarto...

- Nem preciso ver - respondeu ela. - Felicidade é algo que você decide por princípio. E eu já decidi que vou adorar! É uma decisáo que tomo todo dia quando acordo. Sabe, eu tenho duas escolhas: Posso passar o dia inteiro na cama contando as dificuldades que tenho em certas partes do meu corpo que não funcionam bem... ou posso levantar da cama agradecendo pelas outras partes que ainda me obedecem. Cada dia é um presente. E enquanto meus olhos abrirem vou focalizá-los no novo dia e também nas boas lembranças que eu guardei para esta época da vida. A velhice é como uma conta bancária: Você só retira daquilo que você guardou. Portanto, the aconselho depositar um monte de alegria e felicidade na sua Conta de Lembranças. E como você vê, eu ainda continuo depositando. Agora, se me permite, gostaria de lhe dar uma receita: 1 - Jogue fora todos os números não essenciais para sua sobrevivência. 
2- Continue aprendendo. Aprenda mais sobre computador, artesanato, jardinagem, qualquer coisa. Não deixe seu cérebro desocupado.

3- Curta coisas simples.

4-Ria sempre, muito e alto. Ria até perder o fôlego.

5- Lágrimas acontecem. Aguente, sofra e siga em frente. A única pessoa que acompanha você a vida toda é você mesmo. Esteja vivo, enquanto você viver.

6- Esteja sempre rodeado daquilo que você gosta: pode ser familia, animais, lembranças, música, plantas, um hobby, o que for. Seu lar é o seu refúgio.

7-Aproveite sua saúde. Se for boa, preserve-a. Se está instável, melhore-a. Se está abaixo desse nivel, peça ajuda.

8- Diga a quem você ama que você realmente o ama, em todas as oportunidades. E lembre-se sempre que: A vida não é medida pelo número de vezes que você respirou, mas pelos momentos em que você perdeu o fôlego... de tanto rir: de surpresa... de êxtase... de felicidade!

Simples assim!

Autor desconhecido

Fonte: UMA LIÇÃO... (2014).

O segundo texto foi a letra da música Resposta ao Tempo, dos compositores Aldir Blanc e Cristovão Bastos, na voz de Nana Caymmi.

Tanto o primeiro texto, quanto à letra desta música me emocionam pessoalmente, acho que isso também fez com que a aula fosse de verdade muito sensível e literalmente emotiva.

\section{Resposta ao tempo}

Batidas na porta da frente é o tempo

Eu bebo um pouquinho pra ter argumento

Mas fico sem jeito, calado, ele ri

Ele zomba do quanto eu chorei

Porque sabe passar e eu não sei

Um dia azul de verão, sinto o vento

Há folhas no meu coração é o tempo

Recordo um amor que perdi, ele ri

Diz que somos iguais, se eu notei

Pois não sabe ficar e eu também não sei

E gira em volta de mim, sussurra que apaga os caminhos

Que amores terminam no escuro sozinhos

Respondo que ele aprisiona, eu liberto

Que ele adormece as paixóes, eu desperto 
E o tempo se rói com inveja de mim

Me vigia querendo aprender

Como eu morro de amor pra tentar reviver

No fundo é uma eterna criança

que não soube amadurecer

Eu posso, ele náo vai poder me esquecer

No fundo é uma eterna criança

que não soube amadurecer

Eu posso, ele não vai poder me esquecer

Fonte: Blanc e Bastos (2015).

\section{Algumas considerações sobre a leitura}

Em diversos campos e em muitas dimensóes, a leitura pode ser considerada um ponto relevante na aprendizagem de uma língua.

Considero importante que os professores (especificamente de PLE) saibam delimitar algumas das muitas definiçóes sobre leitura e tenham claro o objetivo que se quer alcançar ao ler ou ao propor uma leitura a alguém.

A leitura é um ato de prazer, de aprendizagem e de descoberta, mas se alguém é obrigado a ler um determinado texto para prestar contas sobre o assunto nele tratado ou para realizar algum exame que o ponha em estado de tensão, de ansiedade, certamente não encontraremos aqui leitores que realizam o ato de ler com prazer, mas sim como obrigação profissional, acadêmica, etc.

É preciso levar em conta que alguns fatores ${ }^{1}$ vão influenciar no trabalho de ensino de leitura em aula; um deles é o cognitivo, que é tratado, por exemplo, nos estudos de Kleiman (2001, p.31), nos quais ela afirma que, em geral,

[...] sấo aspectos ligados à relaçấo entre o sujeito leitor e o texto enquanto objeto, entre linguagem escrita e compreensão, memória, inferência e pensamento. Eles tentam incorporar aspectos socioculturais da leitura, uma vez que vão desde a percepção das letras até o uso do conhecimento armazenado na memória.

Variados são os conceitos e as definiçóes de leitura que encontramos, pois cada indivíduo tem um objetivo a atingir quando está lendo.

Orlandi (1988, p.9) diz que:

[...] Leitura não é uma questão de tudo ou nada, é uma questão de natureza, de condiçốes, de modos de relaçấo, de trabalho, de produção de sentidos, em

1 Os fatores podem ser os mais variados: memória, conhecimento cultural, histórico, bibibliográfico, etc. 
uma palavra: de historicidade. [...] A leitura é o momento crítico da produção da unidade textual, da realidade significante [...].

Pode-se entender, a partir da perspectiva de Orlandi (1988), que a leitura se divide num sentido amplo, num restrito e outro ainda mais restrito, começando respectivamente por atribuição dos sentidos, metodologia da aproximação entre texto e leitor e alfabetização, no caso dos pequenos leitores.

Por outro lado, Kleiman, (1997, p.27) afirma que:

O mero passar de olhos pela linha não é leitura, pois leitura implica uma atividade de procura por parte do leitor, no seu passado, de lembranças e conhecimentos, daqueles que são relevantes para a compreensáo de um texto que fornece pistas e sugere caminhos, mas que certamente não explicita tudo o que seria possível explicitar.

Kato (1995, p.106-107) define a leitura da seguinte forma:

A leitura pode ser entendida como um conjunto de habilidades que envolvem estratégias de vários tipos:

- a de encontrar parcelas significativas do texto;

- a de estabelecer relaçóes de sentido e de referência entre certas parcelas do texto;

- a de avaliar a verossimilhança e a consistência das informações extraídas;

- a de definir o significado e o efeito pretendido pelo autor do texto.

Resumindo, pode-se dizer que ler não é apenas decodificar sinais gráficos que estáo escritos em um determinado idioma, mas passar daí para um nível de compreensão da informação a ser transmitida pelo texto. Daí a importância de selecionar e conhecer o que vai ser indicado e/ou trabalhado numa aula de leitura.

No ensino da Língua Portuguesa como LE, deparamo-nos, muitas vezes, com esse tipo de situação: vários leitores que podem ou não ter algum conhecimento do assunto a ser lido e isso, igualmente, pode ou náo influenciar na hora da leitura.

Se o aluno gosta de ler, terá grandes probabilidades de ver a leitura como um ato de prazer e descoberta; vai certamente mergulhar nos contos e narraçóes que encontrar à sua frente, o que é fundamental para aprender um idioma estrangeiro.

\section{A estratégia}

Uma vez escolhidos os textos a serem trabalhados, dividi a aula em partes: leitura do primeiro texto, correção de erros fonéticos cometidos durante a leitura, significado de palavras novas, reconhecimento dos verbos a serem revisados, frases com os verbos 
que consideramos mais usados, audição da música (segundo texto) com a letra trocada e umas lacunas para serem preenchidas durante o áudio, significado de palavras, reconhecimento dos verbos, impressão, comentários, sugestóes por parte dos alunos. Nessa hora, o aluno fica livre para comentar algo pessoal ou criar a história que quiser, pois o objetivo é praticar os verbos (e as expressóes) aprendidos, e, finalmente, a avaliação da aula.

\section{A leitura do primeiro texto por parte dos alunos e da professora e a correção dos possíveis erros fonéticos}

Lemos, corrigimos os possíveis erros fonéticos cometidos durante a leitura e vimos o vocabulário desconhecido. A leitura foi feita duas vezes no esquema de rodízio.

Esse texto é por si, bem emotivo, pois trata da perspectiva de uma mulher idosa entrando numa residência pela primeira vez e seu modo de ver a vida, de encarar aquela situação, direito a dar uma lição de vida ao leitor.

Para os mais sensíveis, o texto serviu de reflexão, para outros, foi apenas um texto desses que circulam na internet como clichês ou correntes que as pessoas mandam querendo "mudar a sua vida". Seja como for, o texto mexeu com os sentimentos pessoais e isso propiciou a interação de troca de impressóes, opinióes, segredos e curiosidades. Foi quase uma aula-terapia.

Aliás, muitas das aulas de PLE são aulas-terapias, nas quais a maioria dos alunos vem cansada do trabalho, do stress ou da pressáo nos seus postos e se sentem outras pessoas ao encontrarem uma aula dinâmica, atraente e divertida.

Não muito diferente do encontro em sala de aula em uma escola de línguas, é o encontro do professor que vai às empresas para as aulas. Vemos desde alunos que deixam propositalmente os telefones em suas mesas para poderem estar concentrados e aproveitarem as aulas até aqueles que trazem os celulares, as agendas e náo desconectam. Nesse caso, cabe ao professor dirigir a sua aula de modo que se tiver que ser interrompida por um telefonema, vai ter que fazê-lo... (muitas vezes os alunos são executivos e têm aulas no horário de trabalho). Começar e recomeçar um assunto pode ser bem cansativo, mas se não houver outra forma, assim será o trabalho.

Com relação à correção dos possíveis erros de pronúncia na hora da leitura, costumo ser bastante exigente com os meus alunos no que diz respeito à fonética. Considero que falar bem não é só conhecer a gramática, mas pronunciar corretamente e, quando se trata de alunos de origem hispânica, a dificuldade maior reside justamente no fato de que uma palavra mal pronunciada pode significar outra

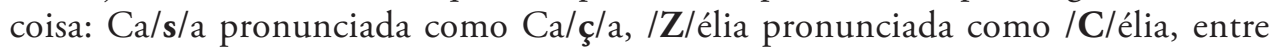
outros.

Por isso, a leitura faz parte do processo e deve ser trabalhada de maneira lúdica, divertida, curiosa, emocionante, envolvente e o professor vai ser esse mediador. Daí a importância de saber escolher bem seu material de acordo com o perfil dos alunos. 
Assim, vai poder traçar seus objetivos, sua estratégia, sua avaliação e finalizar o conteúdo trabalhado com uma revisão bem feita, dinâmica e eficaz, comprovando que seu aluno aprendeu, conseguiu atingir a sua proposta e agora é capaz de por em prática de forma natural, sem bloqueios nem medos.

\section{Aprendendo novo vocabulário}

Como já se sabe, ler e não entender o que está sendo lido gera certa frustração no leitor. Em uma aula de PLE, consideramos que o aluno vai adquirindo confiança para falar na medida em que ele vai aprendendo e dominando um novo vocabulário. Essa etapa é natural, mas deve ser bem trabalhada pelo professor. De nada vai adiantar simplesmente dizer o significado ou fazer a tradução das palavras que o aluno náo conhece e deixá-las sem contexto ou exemplos, para que o aluno associe essas palavras com outras possibilidades de uso, que não seja aquele contexto onde ele as encontrou. Por isso, a importância do reforço do uso do novo vocabulário em diferentes situaçóes.

O processo de integração do aluno de PLE como leitor interage com a associação que ele faz das frases umas com as outras, das palavras conhecidas, da compreensão global do texto passando à percepçáo do contexto. Por isso, se a leitura for interrompida a cada palavra desconhecida para perguntar (no caso de ter diante dele seu professor) ou ir ao dicionário, no fim das contas, o aluno vai precisar de uma segunda ou de uma terceira leitura para perceber o significado do texto.

Quando a leitura é feita de forma natural, sem interrupções, o professor vai propiciando ao aluno a oportunidade de começar a pensar em português - no nosso caso. Talvez seja um trabalho mais intenso e nem todos os alunos vão responder da mesma forma, pois isso, vai depender do conhecimento de mundo e de outros idiomas que esse aluno tenha. Esses fatores são relevantes no processo de leitura por parte de um aluno de origem hispânica num curso de PLE. Levamos em consideração a proximidade dos idiomas espanhol e português, a lista de falsos amigos que esses dois idiomas apresentam, a ideia da competência imediata, entre outros fatores como: o tempo em que o aluno está estudando, se ele costuma ler muito ou não, se ele gosta ou não de ler, etc.

\section{Reconhecimento dos verbos nos textos}

Essa é a parte do trabalho lúdico com a gramática, pois assim fica fácil para o aluno e ele acaba interagindo de forma natural e poderá praticar os verbos nas suas falas, sem precisar memorizar infinitas listas e diversos tempos verbais.

Pois bem, no primeiro texto encontramos mais variedade de tempos verbais: presente, pretérito perfeito, imperfeito, mais-que-perfeito, imperativo, gerúndio, futuro do pretérito. Separamos apenas os tempos que queríamos revisar. Uma vez terminada essa 
etapa aplicamos os verbos em frases orais e escritas feitas pelos alunos, mas em outros contextos, o que possibilitou a exploração do uso desses verbos e, consequentemente o aparecimento de novo vocabulário.

Nesse momento é interessante que o professor sugira que os alunos trabalhem em pares, pois desse modo eles podem conversar, perceber como o colega atua, sentir as mesmas dificuldades (ou não) que o outro. É um momento também de autoestima, saber que o outro tem a mesma dúvida e/ou dificuldade, que pode fazer perguntas semelhantes, etc.

\section{O segundo texto: a música}

Em geral os alunos de PLE ficam esperando essa hora da aula. A MPB é o material mais rico e diversificado que um professor tem em suas máos para aulas de PLE, sobretudo no estrangeiro.

Com a letra de Resposta ao Tempo para completar e corrigir as palavras trocadas, os alunos ouviram a música duas vezes, fizeram a correçáo com a letra original e, como fizemos com o primeiro texto, vimos o vocabulário e retiramos os verbos que apareceram, mas desta vez não precisaram formar frases ou contextos, simplesmente observamos e comentamos em que tempo e pessoa estavam conjugados.

\section{Comentários por parte dos alunos: avaliação}

Sim, definitivamente o texto mexeu com os sentimentos dos alunos. No primeiro grupo, onde tínhamos seis alunos de nacionalidades diferentes, embora de origem hispânica, a reação foi diversa: um dos alunos achou o texto muito "comum", náo se sentiu táo sensibilizado quanto seus cinco colegas que se emocionaram com o teor do texto e começaram a falar um pouco de suas experiências mais pessoais, de como gostariam de aproveitar mais o tempo, de viajar mais, estar com suas famílias e amigos, etc. Desse momento surgiram novas palavras, novas expressóes, que fomos colocando na lousa e formando ideias a partir do que falavam. Foi uma experiência muito enriquecedora. A música deu o toque final à emotividade e foi quando eles foram vendo as expressóes ligadas ao tempo, fazendo uma leitura dos dois textos. Desse grupo surgiu a ideia de que cada um trouxesse para as aulas posteriores algum texto ou alguma letra de música em português, que pudessem ter algum significado para eles. Assim, poderíamos continuar o trabalho de revisão de verbos e a prática oral, mas através da leitura de textos trazidos por eles mesmos.

Quando um aluno de PLE lê em texto em português é capaz de ativar seus conhecimentos do idioma fixando novo vocabulário. Deste modo, pouco a pouco, vai deixando de lado o medo e a insegurança na hora de se expressar.

Esse grupo avaliou a aula como positiva, divertida e emocionante. Possibilitou a entrada de novas estratégias de participação por parte deles para as aulas seguintes. 
No segundo caso, na aula com o aluno individual, a reação foi surpreendente: ali na minha frente havia um aluno - presidente executivo de uma empresa - que chorou emotivamente (sem nenhum escrúpulo) ao final da leitura do primeiro texto. Fiquei também emocionada de ver a sua reação e cheguei a cogitar a ideia de não fazer a segunda parte com a música, mas inverti um pouco a ordem das atividades e tudo correu tranquilamente dentro da dinâmica que havia preparado. Antes da música, falamos do texto e ele me contou (usando os verbos nos tempos adequados!) as atividades que fazia fora da empresa, sua predileção por motos, por esportes pouco comuns, e foi falando sobre as coisas da vida cotidiana. Foi excelente, pois imagino que de nenhum outro modo eu conseguiria que ele falasse espontaneamente de vários assuntos com tanta naturalidade.

Esse aluno avaliou a aula também como positiva, diferente, emotiva, atraente e ainda agradeceu a minha sensibilidade em escolher textos tão especiais para as aulas.

\section{Considerações finais}

Sabemos que a teoria e a prática juntas sempre dão bons resultados, mas esses resultados são ainda melhores se o trabalho envolve cognitivamente o aluno.

Os aspectos mais interessantes na nossa experiência com esses dois textos foram a simplicidade do vocabulário encontrado e a interação que os alunos apresentaram com os dois textos.

Trabalhar com a emotividade através da leitura e da música nas aulas de PLE trouxe experiências positivas e uma relação de confiança e cumplicidade entre alunos e professora. Foi possível aproximar o idioma das emoçóes pessoais de cada um, fazendo uma ponte entre a língua portuguesa e as emoçôes até então possíveis de serem expressas no seu idioma materno.

Las emociones no son únicamente los factores más importantes de la vida individual, son también las fuerzas naturales más poderosas que conocemos. (VIGOSTSKY, 2004, p.113).

\section{AN EXPERIENCE IN PLE CLASSES: THE SENSITIVITY AND EMOTIONALITY IN READING CLASSES AND TEACHING OF VERBS IN THE PAST TENSE PERFECT AND IMPERFECT}

- ABSTRACT: In this article, I try to show my experience with an activity related to sensitivity in a reading class of a PLE course (Portuguese as a foreign language) for students of Hispanic origin, from the planning stage until the time of evaluation, providing guidance for all the activities used throughout the process. The steps of this process are separated according to the students' 
profile (we work with two specific groups of intermediate level students), the choice of material utilized, the strategies used, the dynamics applied, and the oral assessment, where, to my surprise, the students demonstrated a sensitivity that generated a very emotional environment, resulting in increased trust and complicity. Often these feelings are absent in a classroom, which allows the distance between the teacher and student to be an inhibiting factor at the time of oral practice of the language you are learning. The closeness between people provides a welcoming, pleasant environment which is more conducive to interaction and consequently more sensitive.

- KEYWORDS: Reading. Emotion. Sensitivity. Oral competence.

\section{REFERÊNCIAS}

BLANC, A.; BASTOS, C. Intérprete: Nana Caymmi. Resposta ao tempo. Disponível em: $<$ http://www.vagalume.com.br/nana-caymmi/resposta-ao-tempo.html\#ixzz3RppbzgbD>. Acesso em: 20 maio 2015.

CORALINA, C. Melhores poemas. Seleção e apresentação de Darcy França Denófrio. 3.ed. São Paulo: Global, 2011.

KATO, M. O aprendizado da leitura. 4.ed. São Paulo: Martins Fontes, 1995.

KLEIMAN, A. Oficina de leitura: teoria e prática. Campinas: Pontes, 2001.

Texto e leitor: aspectos cognitivos da leitura. 5.ed. Campinas: Pontes, 1997.

ORLANDI, E. Discurso e leitura. Campinas: Ed. da UNICAMP, 1988.

UMA LIÇĀO de vida. Medplan, Teresina, 16 jul. 2014. Disponível em: <http://www.medplan. com.br/ouca-um-bom-conselho/uma-licao-de-vida,33230 s. Acesso em: 20 maio 2015.

VIGOTSKY, L. S. Teoría de las emociones: estudio histórico-psicológico. Madrid: Akal, 2004. 